\title{
Parte 1 - Representação do rural Resgate histórico-analítico da mobilização e organização dos atingidos por barragens na bacia do rio Uruguai (1970-2015)
}

\author{
Humberto José da Rocha \\ Gerson de Lima Oliveira
}

\section{SciELO Books / SciELO Livros / SciELO Libros}

ROCHA, H.J., and OLIVEIRA, G.L. Resgate histórico-analítico da mobilização e organização dos atingidos por barragens na bacia do rio Uruguai (1970-2015). In: TEDESCO, J.C., SEMINOTTI, J.J., and ROCHA, H.J., ed. Movimentos e lutas sociais pela terra no sul do Brasil: questões contemporâneas [online]. Chapecó: Editora UFFS, 2018, pp. 29-58. ISBN: 978-85-64905-76-4.

https://doi.org/10.7476/9788564905764.0002.

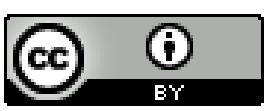

All the contents of this work, except where otherwise noted, is licensed under a Creative Commons Attribution 4.0 International license.

Todo o conteúdo deste trabalho, exceto quando houver ressalva, é publicado sob a licença Creative Commons Atribição $\underline{4.0}$.

Todo el contenido de esta obra, excepto donde se indique lo contrario, está bajo licencia de la licencia $\underline{\text { Creative Commons }}$ Reconocimento 4.0. 


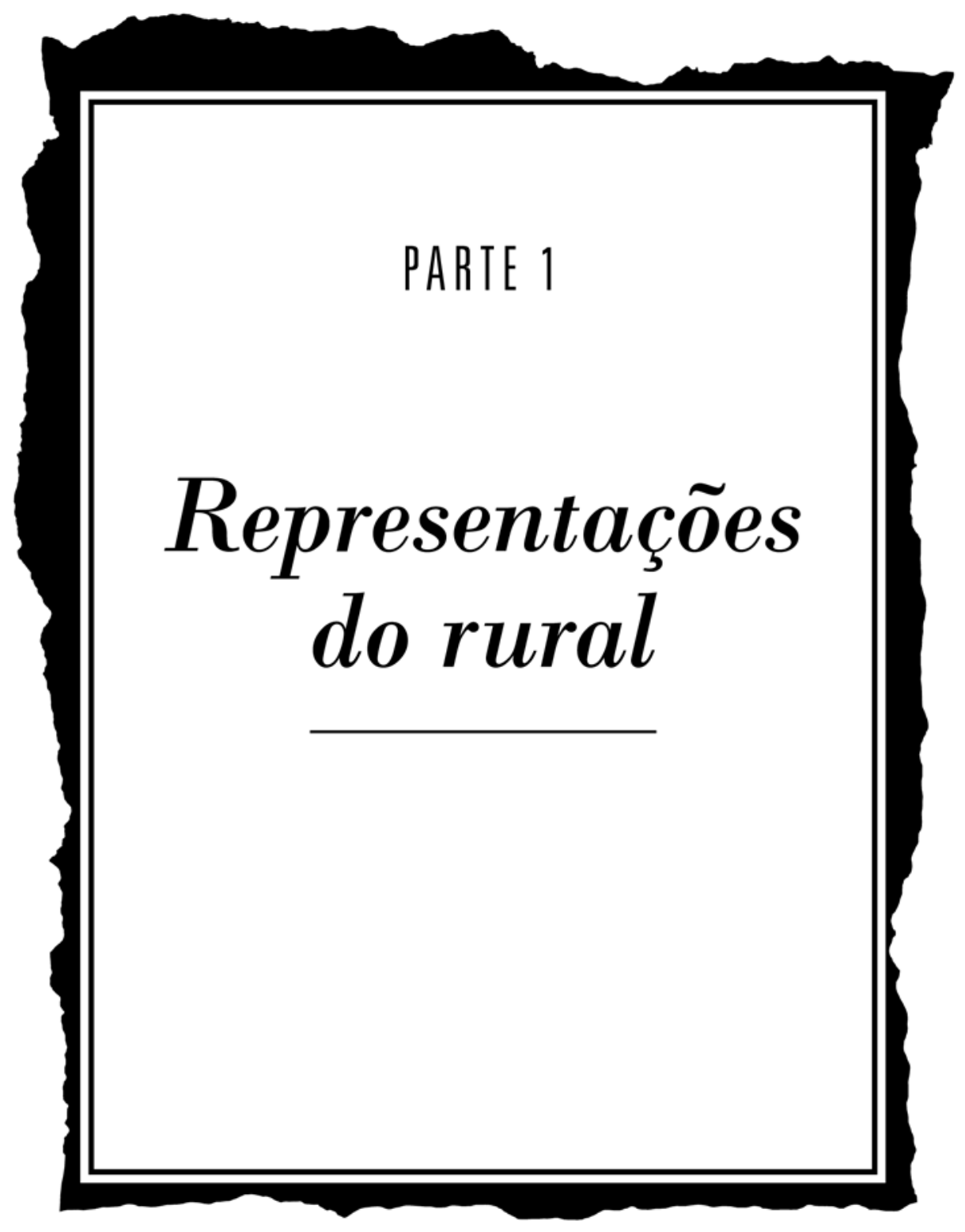




\section{Resgate histórico-analítico da mobilização e organização dos atingidos por barragens na bacia do rio Uruguai (1970-2015)}

Humberto José da Rocha ${ }^{1}$

Gerson de Lima Oliveira ${ }^{2}$

\section{A vertente contextual no berço do rio Uruguai (1970-1985)}

Considerando a hidroeletricidade um processo social no sentido de que produz efeitos e impactos concretos à sociedade, desde a primeira hidrelétrica instalada no Brasil (1883) podemos afirmar que até 1970 a 1980 não havia um planejamento prévio para reassentamento de famílias atingidas por barragens. Nesse período, o remanejamento acontecia "às vésperas da inundação" ou "quase que simultaneamente à subida das águas", como ocorrido nas hidrelétricas de Sobradinho e Itaparica (rio São Francisco-PE) em 1970, Tucuruí (rio Tocantins-PA) e Itaipu (rio Paraná-PR) em 1980 (BERGAMASCO; NORDER, 1996).

Considerando também a mobilização social diante desses impactos gerados pelas barragens identificadas em diferentes regiões do Brasil, como a usina hidrelétrica de Itá (UHE), observamos um salto qualitativo

1 Professor Adjunto da Universidade Federal da Fronteira Sul (UFFS). Contato: humberto.rocha@uffs.edu.br.

2 Professor Adjunto da Universidade Federal do Pampa (Unipampa) e pesquisador do Grupo de Pesquisa Associativismo, Contestação e Engajamento (GPACE) vinculado à Universidade Federal do Rio Grande do Sul (UFRGS). Contato: gerson.oliveira@unipampa.edu.br. 
a esse respeito. Podemos considerar como marco oficial da organização de movimento social contra as barragens o evento que reuniu, aproximadamente, 350 agricultores familiares, em Concórdia-SC, no dia 24 de abril de 1979, quando foi formalizada a Comissão Regional de Barragens (CRAB). A mobilização social baseou-se em notícias dos traumáticos processos vividos por atingidos pelas hidrelétricas instaladas em outras regiões do país. Na bacia do rio Uruguai, a UHE Passo Fundo era a única obra de grande escala instalada até então. Mesmo assim, não se aproximava em tamanho e impacto às demais hidrelétricas do Centro, Nordeste e Paraná. A notícia mais contundente foi o projeto de 22 UHEs pretendidas pela Eletrosul no rio Uruguai no trecho nacional e mais três no trecho da fronteira com a Argentina. As de Machadinho e Itá seriam as primeiras, porém, em virtude da mobilização social, a ordem, em parte, foi invertida. A mobilização caracterizou-se como uma espécie de "serviço" pelas ações pontuais, ainda sem sistematização estratégica e organizacional definidas. No início de 1980, o regime civil-militar apresentava sinais de abertura democrática, e o tema ambiental foi regulamentado regrando o processo de licenciamento. Assim, o movimento social consolidou-se em vista da instalação das UHEs Itá e Machadinho, na divisa entre Santa Catarina e Rio Grande do Sul.

Segundo Jasper, Goodwin e Polletta (2001), a dimensão emotiva é um dos principais elementos de análise das questões sociais, inerente ao fazer humano e aos grupos sociais. É, portanto, algo central na conformação das relações humanas. Nem sempre se festeja a alegria, tampouco a insatisfação; são necessariamente manifestadas diante das adversidades do cotidiano. Em relação aos atingidos por barragens, o grau de insatisfação e insegurança ante os possíveis impactos causados pela construção da barragem coloca em xeque o seu modo de viver. Essa situação, de fato, corresponde a um dos principais fatores de mobilização coletiva.

Outro elemento explicativo de mobilização e organização dos atingidos por barragens vai ao encontro da conceituação de Sidney Tarrow, que 
define como "estrutura de oportunidades políticas" (EOP). Esse conceito visa compreender como as demandas de grupo são manifestadas diante de um cenário oportuno, que dá origem a confrontos políticos. Sustenta que "o confronto político surge como uma reação a mudanças nas oportunidades e restrições políticas em que os participantes reagem a uma variedade de incentivos: materiais e ideológicos, partidários ou baseados no grupo, de longa duração ou episódicos" (TARROW, 2009, p. 38).

No entanto, em um cenário de oportunidades não significa, necessariamente, que confrontos políticos possam ocorrer. Mesmo diante das demandas dos grupos serem pontuais ou estruturais, há que distinguir-se "potencial de mobilização" de "ação de fato". O primeiro representa o estado de latência do confronto, ao passo que o segundo representa a mobilização efetiva que o promove. Nesse sentido, Tarrow apresenta cinco aspectos em que se percebe como essa passagem de potencial em ação pode acontecer: "1) abertura do acesso à participação para novos atores; 2) evidência de realinhamento político no interior do sistema; 3 ) presença de aliados influentes; 4) divisões emergentes no interior da elite; 5) declínio na capacidade do estado de reprimir dissidências" (TARROW, 2009, p. 105).

Em relação ao movimento dos atingidos por barragens (MAB), tema empírico de nossa análise, Rothman (1996) apresenta um estudo importante na perspectiva das EOPs. Sem restringir-se ao arcabouço analítico da escola norte-americana, $\mathrm{o}$ autor apresenta pontos que contribuem para o entendimento de como o MAB passou de latência para a ação de fato num cenário de oportunidades para ações efetivas. Depois de apresentar pontualmente os itens sugeridos por Tarrow (2009) e enriquecidos com apontamentos de ordem geopolítica e social específicos à bacia do Uruguai, Rothman (1996, p. 117) sintetiza a análise das oportunidades políticas da seguinte forma:

No período 1979-83 abriu-se uma estrutura de oportunidades favorável e crescente: a abertura política do regime civil-militar permitiu 
o acesso progressivo de atores antes impossibilitados de ingressar no sistema político; a fragmentação das elites enfraqueceu a posição dos grupos dominantes; a tendência ao uso de repressão pelo regime militar mostrou sinais de enfraquecimento; grupos populares - livres da tutela dos partidos 'populistas' - desenvolveram formas mais autônomas de organização; e vários movimentos populares se reforçaram na fase crescente do ciclo de protesto, dentre eles organizações coletivas que culminaram na formação do Movimento dos Trabalhadores Rurais Sem Terra (MST) e do próprio MAB.

É fundamental percebermos como esse cenário de oportunidades consiste em um dos fatores de explicação da mobilização social, que, com o tempo, culminou na criação do MAB. Além da identificação da estrutura de oportunidades quando da criação do $\mathrm{MAB}$, a análise de Rothman chama a atenção para outro fator importante: a ideia de "ciclos de protesto", que serão abordados com a denominação dada por Tarrow (2009), "ciclos de confrontos".

Os ciclos de confrontos são condicionados pelos cenários de oportunidade e restrição política. Um ciclo é notabilizado por um ou mais eventos de culminância que ajuda a catalisar os elementos dispersos, porém interligados ao longo do processo social que corresponda ao ciclo. Tarrow apresenta a definição do termo como "uma fase de conflito acentuado que atravessa um sistema social”. E, na sequência, acrescenta elementos constituintes do ciclo, como "uma rápida difusão da ação coletiva de setores mais mobilizados para outros menos mobilizados", "criação de quadros interpretativos $^{3}$ de ação coletiva, novos ou transformados", "combinação de participação organizada e não organizada", capacidade de produzir “externalidades que dão aos desafiantes ao menos uma vantagem temporária e permite que superem a fraqueza na sua base de recursos", faz com que o Estado "monte amplas estratégias de reação repressivas ou facilitadoras,

3 Para Benford e Snow (2000), o processo de enquadramento (framing process) consiste em uma "batalha interpretativa" travada pelos movimentos sociais contra seus opositores na definição do próprio conflito e da justiça/legitimidade das posições em disputa. São formas de interpretar a realidade que obedecem a determinados princípios e se confrontam na esfera pública em disputa pela "veracidade" dos processos sociais em questão. 
ou uma combinação de ambas" e, por último, um ciclo de confronto "produz resultados gerais que são mais do que a soma dos resultados de um agregado de eventos desconectados" (TARROW, 2009, p. 182).

Exemplos que combinam esses elementos podem ser identificados na Revolução Francesa de 1789 e nos movimentos de maio de 1968, ambos na França (TARROW, 2009).

A questão geográfica pode ser um fator facilitador da expansão de um ciclo, como as revoluções de 1848 na Europa ou, mesmo, transcendê-la, como a oposição à guerra do Vietnã nos Estados Unidos. O autor apresenta uma série de ciclos que podem ser melhor estudados no que se refere à condição de continuidade ou novidade na relação entre eles. É importante destacar que, ao analisar um ciclo e seus desdobramentos, é necessário atenção para não considerá-lo “apenas como um 'contágio’ da ação coletiva para grupos similares e que fazem as mesmas reivindicações a opositores equivalentes". O autor assinala como característica importante para a análise a "difusão da propensão à ação coletiva" (TARROW, 2009, p. 186).

O título do livro 1968: o ano que não terminou, do jornalista Zuenir Ventura, ilustra um exemplo da relação entre ciclos de confrontos em diferentes partes do mundo, os quais têm ou podem ter relação dentro de um mesmo ciclo. Ventura (1988) apresenta várias crônicas sobre o período ditatorial brasileiro, com recorte temporal do ano de 1968, tendo como pano de fundo, porém, um ciclo que compreende desde a França até o Brasil na luz do ciclo de confrontos notabilizado pelos movimentos de maio de 1968. Restringindo a nossa análise ao caso brasileiro, os vinte anos entre 1968 e 1988 podem ser tomados como um ciclo de confrontos, que culminou no movimento das "Diretas Já" e, consequentemente, a abertura democrática. Nesse ciclo de confrontos está a questão das barragens, tendo como recorte espacial a bacia do rio Uruguai.

O relevo ondulado e o solo pedregoso dificultam a mecanização agrícola nessa bacia. A ocupação do espaço e o modo de vida condizem com tal configuração geográfica já que os agricultores têm na unidade 
familiar a pluriatividade e a reciprocidade, bases da organização da vida social. Esses elementos fundamentam as palavras de Piran (2001) quando define o Alto Uruguai como "um lugar para a agricultura familiar". A partir da configuração geográfica e social da região foi estruturado um parque agroindustrial que, atualmente, é referência mundial em produtos derivados de suínos e aves. No entanto, paralelo a esse desenvolvimento econômico, consideraram-se os reflexos da intensificação dessa atividade no viés social sobre o qual indagamos que desde que os agricultores familiares passaram a desenvolver a suinocultura e a avicultura, através do sistema de integração com as empresas, mesmo que tenham garantido o mercado para o seu produto, isso se deu por meio da relativa perda da autonomia dos que passaram a trabalhar sob as orientações das empresas, tendo que acompanhar um ritmo de modernização de produção em vista da competitividade do mercado.

A agroindústria regional é um elemento importante para o registro histórico que se entende estar diretamente relacionado à questão hidrelétrica. Preponderante na economia a partir do final do século XIX, a crise que a suinocultura atravessou na década de 1970 refletiu de forma importante no contexto político regional. Foi deflagrada pela suposta contaminação dos suínos, a chamada "peste suína africana”, que poderia espalhar-se por todo o país. Diante dessa suspeita, a partir de setembro de 1978, as propriedades identificadas eram interditadas, e os suínos exterminados por pelotões do Exército (POLI, 1999, p. 68).

O evento que envolveu a suinocultura, principal atividade econômica, significou um duro golpe para os pequenos produtores, levantando suspeitas de que tal doença e os decorrentes abatimentos eram parte de uma estratégia das empresas interessadas em debilitar a produção autônoma de suínos no intuito de controlar o mercado na região. A partir da mediação de setores da Igreja (CPT) e do Sindicato de Trabalhadores Rurais (STR), foi feita uma intensa mobilização social que culminou com uma manifestação com mais de vinte mil pessoas na cidade de Chapecó-SC, 
em outubro de 1979, em protesto contra as condições de produção do setor e principalmente contra o que ficou conhecido como a "farsa da peste suína africana" (POLI, 1999, p. 70).

A mobilização social diante dessa questão levou, aos poucos, à diminuição dos abatimentos. Do episódio, o certo é que não ficou comprovada a existência ou o alcance da doença, mas não mudou o fato de que os abatimentos compulsórios tenham prejudicado os pequenos produtores. $\mathrm{O}$ registro desse evento é importante, pois aconteceu na mesma época em que a Eletrosul publicou um estudo do inventário hidrelétrico da bacia do rio Uruguai (outubro de 1979) prevendo a construção de 22 usinas hidrelétricas. Isso significava que grandes áreas de terra seriam inundadas na região. As construções das hidrelétricas de Machadinho e Itá seriam as primeiras a se concretizarem e, diante disso, além do problema do abatimento dos suínos, sobraria para os agricultores familiares locais a ameaça de expropriação.

O estudo realizado pela Eletrosul foi levado ao conhecimento da opinião pública pela ação de grupos que também militavam no contexto nacional da ditadura militar, como igrejas, sindicatos e universidades. No caso da bacia do rio Uruguai, segmentos da Igreja Católica, Igreja Evangélica de Confissão Luterana no Brasil (IECLB), alguns sindicatos de trabalhadores rurais e a Fundação Alto Uruguai para a Pesquisa e o Ensino Superior (Fapes) de Erechim-RS, atual Universidade Regional Integrada (URI), foram os principais mediadores nessa questão desde o plano teórico até a mobilização da população atingida.

Quando das primeiras ações na direção da organização de um movimento social coeso, há que retomarmos o cenário de oportunidade política que, se não determinava a eclosão de movimentos dessa natureza, favorecia a sua estruturação. Nesse contexto, o poder de repressão do Estado foi aos poucos diminuindo em relação ao auge do período militar. A Lei da Anistia, de agosto de 1979, permitiu a volta dos exilados políticos para o país, reforçando o ativismo nas diversas causas sociais. Em novembro do mesmo ano, o fim do bipartidarismo promoveu a divisão das elites 
acarretando o enfraquecimento das oligarquias locais. Em 1983, no Rio Grande do Sul, partidos de oposição na Assembleia Legislativa investigaram e publicaram um relatório sobre a questão das barragens, disponibilizando suas instalações para o "I Encontro estadual sobre a construção de barragens na bacia do rio Uruguai", reunindo diferentes segmentos sociais sobre a questão. Essa conjuntura política atrelada a eventos locais representou um ambiente favorável para a emergência de um movimento social ante o projeto da empresa hidrelétrica.

De acordo com McAdam, Tarrow e Tilly (2001), uma onda de protestos consumava-se a partir da combinação do surgimento de uma janela de estrutura de oportunidades políticas (EOP) com a própria capacidade de organização dos movimentos sociais, influenciada por uma série de fatores, dentre os quais os imperativos contextuais. Em suma, a organização dos atingidos por barragens na bacia do rio Uruguai foi possibilitada pela EOP, que se abriu pelo compartilhamento de uma indignação coletiva diante da ameaça da construção de barragens e pela capacidade de organização. No que diz respeito à organização coletiva, uma série de fatores foram cruciais, dentre os quais a capacidade de os atingidos se manterem mobilizados, de captarem recursos para sua organização e o papel desempenhado pelos mediadores, isto é, indivíduos e grupos que forneceram suporte material e simbólico para a incipiente mobilização dos atingidos por barragens.

Entre as ações mais expressivas dos mediadores, algumas merecem destaque: a atuação da Igreja Católica, que ocorreu por meio do recrutamento de participantes para o movimento social de setores da Igreja, como a Comissão Pastoral da Terra (CPT), a Pastoral da Juventude Rural (PJR) e o Ministério Eucarístico; as estações de rádios de Concórdia, Marcelino Ramos e Aratiba foram utilizadas; a disponibilidade de pessoal para a organização do movimento dos chamados "liberados". A IECLB serviu de canal de ligação entre os atingidos da bacia do rio Uruguai com outros locais, como Itaipu e Sobradinho, intermediou apoio financeiro na organização evangélica alemã Brot Fur die Welt (pão para o mundo), além de "liberar" 
pessoal para a organização do movimento social. A Fapes, além da pesquisa dos impactos socioeconômicos, importantes para a fundamentação da mobilização e organização em torno do problema, angariou recursos de duas ONGs: Comitê Católico Contra a Fome e Desenvolvimento (CCFD), da França, e Obra Episcopal da Igreja Católica da Alemanha para a Cooperação ao Desenvolvimento (Misereor), da Alemanha. Além dessas, foi importante a atuação do Sindicato de Trabalhadores Rurais (STR) na perspectiva de "sindicalismo combativo", uma vez que estabelecia uma ligação mais efetiva entre essas instituições e os trabalhadores rurais, bem como disponibilizava as estruturas físicas dos sindicatos para a organização do movimento social (ROTHMAN, 1996).

A evolução do movimento social aconteceu paralelamente à apresentação de novos projetos hidrelétricos por todo o Brasil. O plano 2010, elaborado pela Eletrobras, previa a construção de cerca de duzentas usinas hidrelétricas no país. Diante dessa estimativa, o movimento se articulou e, em março de 1991, na cidade de Brasília, realizou o "I Congresso Nacional dos Atingidos por Barragens", onde se oficializou o Movimento Nacional dos Atingidos por Barragens (MAB). A CRAB passou a responder pela $\mathrm{MAB} /$ Região Sul, embora continuasse organizada na estrutura apresentada anteriormente (comissões locais e regionais), a partir desse momento passou a responder pelo movimento nacional.

\section{A consolidação do movimento social: Itá e Machadinho (1985-2000)}

Na medida em que o movimento se consolidava, sua estrutura buscava adequar-se de maneira a abranger toda a bacia hidrográfica. Nesse momento o movimento social passa de uma estrutura de "serviço", com atuações pontuais a partir dos mediadores, para uma organização em 
forma de "movimento", ${ }^{4}$ sistematizando as ações e formando novos ativistas e lideranças (MORAES, 1996a; REIS, 2007). Nessa linha, em dezembro de 1983, foi instituída uma executiva regional para a liderança do movimento. Essa executiva compreendia: dois atingidos (base), dois componentes da comissão inicial (CR), um diretor de STR, um agente da CPT, além de assessores. Nesse momento, a "regional" correspondia apenas às áreas afetadas pelas duas primeiras hidrelétricas, UHE Machadinho e Itá, abrangendo apenas parte da bacia do rio Uruguai, onde era prevista a construção de 22 barragens.

Em março de 1984, a CRAB organizou um abaixo-assinado que reuniu 1.016.000 de assinaturas, deixando claro no cabeçalho do documento a sua posição de "não às barragens" (MORAES, 1996a). Em março de 1985 reuniram-se representantes de 24 municípios regionais na cidade de Erechim-RS com o objetivo de consolidar a atuação da Crab em toda a bacia. A partir dessa reunião, o movimento passou a contar com quatro comissões regionais: R1 - Machadinho e Itá; R2 - Itapiranga e Iraí; R3 Lages; R4 - Chapecó. Em 1986 foi acrescentada a R5 - Missões ou Garabi e Roncador. Com essa conformação, ampliou-se a área de atuação do Movimento na Bacia Hidrográfica, e a Crab foi legitimada como porta-voz dos atingidos. Em 23 de janeiro de 1986, através das portarias nº 86 e 87, o Ministério das Minas e Energia previu a participação de representantes do movimento em "grupos de trabalho" para a avaliação dos impactos na construção das hidrelétricas de Itá e Machadinho (MORAES, 1996a).

Em 29 de outubro de 1987, um acordo entre a CRAB e a Eletrosul (ratificando o documento PRE-692/86, de 7/10/1986) assegurava que "nenhuma obra" seria realizada "dentro dos rios sem prévia indenização ou reassentamento dos atingidos de cada barragem, Itá e Machadinho", além

4 Por "movimento social" entende-se e emprega-se a definição de Mario Diani (2000, p. 389) que compreende, genericamente, como "redes formais e informais de atores (organizações, grupos e indivíduos) engajadas em conflitos em torno de interesses materiais ou simbólicos, baseadas em identidades compartilhadas". 
de estabelecer que as famílias atingidas fossem compensadas mediante três alternativas:

terra por terra, mediante a apresentação de áreas quantas necessárias, preferencialmente na região, ou nos três Estados do sul, com características agrícolas e infraestrutura não inferiores às áreas atingidas; indenização por dinheiro com a participação dos atingidos na determinação dos preços das terras e benfeitorias;

garantia de participação em projetos de reassentamento para todos os sem-terra atingidos pelas barragens de Itá e Machadinho, em áreas dos três estados do sul, com características agrícolas e infraestrutura não inferiores às atingidas pelas barragens (MORAES, 1996a).

Os pontos desse acordo histórico podem ser percebidos nos "termos de acordo" firmados nas hidrelétricas subsequentes.

Em 1989, a Constituição estadual do Rio Grande do Sul previa a instituição de um grupo de trabalho com a participação de representantes da CRAB e de técnicos para a promoção de um "amplo debate público sobre o Projeto Energético Brasil ano 2001, suas repercussões para o Rio Grande do Sul e alternativas a sua Implantação" (MORAES, 1996a). A partir das portarias ministeriais, da Constituição estadual, da garantia de participação em grupos de trabalhos e do acordo com a Eletrosul, a CRAB firmava-se como representante legítima da causa na bacia hidrográfica do rio Uruguai.

Entre 19 e 21 de abril de 1989 ocorreu, em Goiânia-GO, o I Encontro Nacional dos Atingidos por Barragens, quando se decidiu pela organização do movimento em âmbito nacional. Em março de 1991, na cidade de Brasília, oficializou-se o Movimento dos Atingidos por Barragens (MAB) e, a partir de então, a nacionalização do movimento cujas ações se tornaram maiores e mais frequentes em todo o país. Entre 11 e 14 de março de 1997 ocorreu, em Curitiba-PR, o I Encontro Internacional de Atingidos por Barragens, envolvendo mais de vinte países. Nesse encontro, além de discussões em torno da luta contra as barragens, instituiu-se o dia 14 de março como Dia Internacional de Luta Contra as Barragens e pelos Rios, 
pela Água e pela Vida (ALMEIDA, 2004). Esse foi o processo de estruturação do $\mathrm{MAB}$ que, a partir da bacia do rio Uruguai, tomou proporções nacionais e internacionais, militando em cada nova hidrelétrica a ser instalada.

As duas primeiras hidrelétricas - Itá e Machadinho - começaram a ser instaladas em 1991 e 1996, entrando em operação em 2000 e 2001, respectivamente. Além de inaugurarem a exploração sistemática da bacia, essas duas obras representam marcos na estruturação e consolidação do MAB como movimento social antagônico. Em síntese, foi um momento de desinformação, incerteza, articulação e luta dos atingidos ante os projetos capitaneados pelo Estado brasileiro. Um aspecto importante desse período é o fato de que, a partir de 1997, o setor elétrico foi reestruturado, e esses projetos passaram a ser conduzidos pela iniciativa privada (SANTOS; NACKE, 2001; BOAMAR, 2003; ALMEIDA, 2004). Embora essa mudança tenha ocorrido no percurso da instalação, as indenizações e os reassentamentos, especialmente na de Itá, foram encaminhados ainda na gestão estatal. Porém, nas usinas subsequentes - UHE Quebra Queixo, Barra Grande, Campos Novos e Foz do Chapecó -, a mudança ficou mais evidente para os movimentos sociais. O novo cenário do setor elétrico trazia novos atores e estratégias que acentuaram a assimetria nas relações de poder inerentes à questão hidrelétrica (ROCHA, 2013). Um novo período começava para o movimento social.

\section{A privatização, os novos atores e as estratégias: Quebra Queixo, Barra Grande, Campos Novos e Foz do Chapecó (2000-2015)}

Como referimos na seção anterior, no período de instalação das duas primeiras hidrelétricas a mudança estrutural no setor elétrico mudaria drasticamente a relação entre os propositores das hidrelétricas e o movimento social. Ainda na década 1980, o neoliberalismo representava uma tendência mundial, capitaneada principalmente pelos governos Thatcher 
(Inglaterra), Reagan (Estados Unidos) e Pinochet (Chile). No Brasil, a abertura democrática e a eleição de Fernando Collor de Mello marcaram o início do processo no país. O Plano Nacional de Desestatização (PND), instituído pela Lei $\mathrm{n}^{\circ}$ 8.031, de 12 de abril de 1990, deu diretrizes básicas para a organização da economia em todos os setores. O neoliberalismo, enquanto tendência global, aconteceu de forma exemplar no Brasil, que teve o maior pacote de privatização do mundo. Entre os anos 1990 e 2002, dos $48,3 \%$ do capital estatal transferido para a esfera privada, $31 \%$ couberam ao setor de energia elétrica (GONÇALVES JR., 2007, p. 25).

$\mathrm{Na}$ esteira das privatizações, a Eletrosul, responsável pela hidreletricidade na bacia do rio Uruguai, foi dividida em duas partes: a Estatal, responsável pela transmissão de energia; a Gerasul (iniciativa privada), responsável pela geração de energia, assumindo todas as usinas hidrelétricas da Eletrosul em operação ou em projeto. Em 1998, essas hidrelétricas passariam para o controle da Tractebel Energia, uma empresa belga pertencente ao grupo GDF Suez S.A., originado na França.

O governo Fernando Henrique Cardoso sancionou a Lei no 8.987, de 13 de fevereiro de 1995, que dispõe sobre o regime de concessão e permissão da prestação de serviços públicos. Assim, ofereceu as linhas gerais para organização, tendo na Lei ${ }^{\circ}$ 9.074, de 7 de julho de 1995, as normas para a outorga e prorrogações das concessões e permissões específicas para o setor hidrelétrico. Na mesma linha, a Lei $n^{\circ} 9.427$, de 26 de dezembro de 1996, ao instituir a Agência Nacional de Energia Elétrica (Aneel), conferiu ao governo a postura de regulador do sistema hidrelétrico, visto que a agência foi criada com a finalidade de regular e fiscalizar a produção, transmissão, distribuição e comercialização da energia elétrica em conformidade com as políticas e diretrizes do governo federal.

A partir desse marco regulatório, o Estado assumiu definitivamente a condição de parceiro da iniciativa privada na instalação de hidrelétricas. No governo Lula isso foi ratificado através da Lei no 11.079, de 30 de dezembro de 2004, que estabelece as normas gerais para as parcerias 
público-privadas (PPP). Segundo a lei, os projetos de grande escala, como as hidrelétricas, passam a ser conduzidos por sociedades de propósitos específicos (SPE), que têm sua criação em razão da obra (usina) que pretendiam instalar e operar.

A primeira usina instalada integralmente com esse regulamento foi a UHE Quebra Queixo, no rio Chapecó, entre os municípios de Ipuaçu e São Domingos-SC. Embora de porte reduzido em relação às UHE Itá e Machadinho, a instalação dessa hidrelétrica assumiu os mesmos contornos dramáticos das outras. Todavia, aqueles que viam a obra como uma chance de prosperidade tiveram uma oportunidade também no que diz respeito à negociação. Segundo Baggio (2003), a UHE Quebra Queixo apresentou a mesma característica de "desinformação" que ajudou a inserir as hidrelétricas anteriores na bacia. Anteriormente, luta do MAB era contra o Estado, especialmente um Estado repressor, que negava o diálogo e expropriava os cidadãos. Nesse novo cenário de privatização, a "participação" dos atingidos seria "viabilizada" e "incentivada" pelos próprios propositores das obras.

A organização da Associação dos Atingidos pela Barragem do Quebra Queixo nos municípios de São Domingos e Ipuaçu (Asabsi) foi uma iniciativa de 16 pessoas da localidade que se uniram com o apoio dos propositores da usina para intermediar as negociações para facilitar no processo. Do ponto de vista das negociações, uma falha por parte da associação pode ser apontada: o fato de homologar na "Proposta de políticas e ações de remanejamento da população atingida pelo empreendimento" a possibilidade de reassentamento fora da região, conforme desejo manifestado pelos atingidos. O que acabou sendo acordado foi a tomada de preço e a consequente possibilidade de remanejamento populacional ampliada para o sudoeste do Paraná. Essa relativa distância do lugar de origem desmobilizou a opção por reassentamento. Já no processo de negociação, as reuniões entre atingidos e consórcio eram costumeiramente antecedidas por reuniões entre a associação e o consórcio de forma que 
as decisões já estariam tomadas a priori. Pode ser observado no processo de negociação que os casos apoiados pela associação tiveram um tratamento diferenciado por parte do consórcio em detrimento aos casos que não contavam com tal intermediação (BAGGIO, 2003, p. 64-68). Dessa forma, o papel da associação teve uma dupla função no processo. Além de favorecer a legitimidade do projeto, a associação comprometeu o protagonismo ocupado pelo MAB em casos anteriores. Através desse controle do fluxo de negociação (ROCHA, 2014), os consórcios passaram a fomentar a individualização do processo, o que consistiu numa maior inovação nas estratégias de negociação, cujo resultado foi o enfraquecimento da organização coletiva dos atingidos.

Outra hidrelétrica importante do período começou a ser instalada antes da Quebra Queixo e por sua envergadura e problemas ambientais só seria concluída posteriormente. A UHE Barra Grande foi instalada no rio Pelotas entre os municípios de Pinhal da Serra-RS e Anita Garibaldi-SC. Essa hidrelétrica ficou mundialmente conhecida pelo grave problema ambiental detectado durante a instalação. Ocorreu que o estudo de impacto ambiental e o consequente relatório de impacto ambiental (Eia-Rima) negligenciaram informações sobre uma área de 7.650 hectares de cobertura florestal primária (mata de araucária). Em estágios médios e avançados de regeneração, foi desqualificada como "capoeirão" e diminuída na extensão em que seria alagada (PROCHNOW, 2005, p. 6-7). Não obstante os problemas ambientais na perspectiva analisada por Zen (2005, p. 51), o caso de Barra Grande deu um "novo fôlego à luta pela moralização dos Estudos de Impacto Ambiental e à atuação dos órgãos ambientais oficiais que têm sido 'atropelados' pelo discurso de crescimento econômico e pela influência exercida pelo grande capital no governo Lula”. De fato, o que se viu nesse caso foi uma aproximação entre os atingidos, representados pelo MAB, organizações não governamentais (ONGs), especialmente da área ambiental, e a imprensa internacional, que passou a tratar o problema como exemplo de negligência ambiental. 
A de Barra Grande ofereceu ainda uma oportunidade de explicitar outro ponto importante desse período para o movimento social, ou seja, a chegada do Partido dos Trabalhadores (PT) ao governo federal. O cenário de oportunidade política que mencionamos nas seções anteriores compreendeu o processo em que as lutas populares se organizaram originando o PT e o MAB como braços de um mesmo corpo ideológico. Na do Alto Uruguai, as lideranças do MAB eram as mesmas que militavam no PT. Com a subida do partido ao governo, a relação entre o movimento social e o partido abriu canais de interlocução do movimento com a esfera político-estatal, porém essa relação seria tensionada. Em estudo sobre a UHE Barra Grande, Rossato (2008, p. 65) assinala que os "movimentos sociais, entre os quais o $\mathrm{MAB}$, desacreditavam a via partidária como instrumento político para a condução da nação". Isso fica evidente em casos em que as lideranças do movimento manifestam certo incômodo diante da contradição que enfrentaram ao fazer campanha política para o mesmo partido, que, muitas vezes, enquanto governo, promoveu a instalação de hidrelétricas na região. Dessa forma, o MAB distanciou-se sensivelmente do PT e passou a atuar alinhado à Via Campesina, ${ }^{5}$ da qual era membro desde 1998.

A aproximação com o campesinato reforçou a principal forma de luta do movimento dos atingidos por barragens: a "pressão popular" (MAB, 2008, p. 27). Tanto que as ações de mobilização social, como passeatas, acampamentos nas vias de acesso e ocupação de canteiros de obras das barragens, podem ser percebidas nos diferentes locais de conflito. Em resposta a esses movimentos de pressão popular, pode-se dizer que a estratégia da criminalização, que não é recente na história do Brasil, assumiu uma nova roupagem no contexto neoliberal. Essa estratégia procurou

5 A Via Campesina surge em abril de 1992 a partir de uma reunião de dirigentes camponeses de vários países em Manágua, na Nicarágua, quando da realização do Congresso da União Nacional de Agricultores e Pecuaristas. Desse encontro surge a organização internacional composta por movimentos sociais e organizações de todo o mundo. A Via Campesina coordena e visa articular os processos de mobilização social de organizações camponesas de pequenos e médios agricultores, trabalhadores agrícolas, mulheres camponesas e comunidades originárias da Ásia, África, América e Europa em nível internacional. 
enquadrar as ações do movimento social como "crimes", entre os quais "dano", "esbulho possessório", "furto simples e qualificado", "sequestro e cárcere privado", "formação de quadrilha", "incitação ao crime" e "apologia ao crime", tudo previsto no Código Penal Brasileiro (MNDH, 2006, p. 14-15). Referindo-se às ações que foram movidas contra militantes do MAB por ocasião de movimentos de resistência na bacia do rio Uruguai, o Anexo III de um relatório produzido pelo $\mathrm{MAB}$ menciona, além do que já foi relacionado, acusações de natureza criminal, como dano ao patrimônio particular, invasão de áreas de segurança nacional, descumprimento de decisão judicial, crime contra a liberdade do trabalho, ameaça aos funcionários das empresas, destruição de marcos das barragens, roubo de bens nos canteiros de obras, obstrução de vias públicas, perturbação do sossego público, extorsão, lesões corporais, constrangimento ilegal e vias de fato. Já na vara cível, o mesmo documento apresentava ações de reintegração de posse, obrigação de não fazer, interdito proibitório, cautelar inominada e de indenização (MAB, 2005).

Nesse cenário de pressão popular e consequente criminalização dos movimentos sociais é exemplar o caso da UHE Campos Novos, instalada no rio Canoas, entre os municípios catarinenses de Campos Novos e Celso Ramos. O processo de instalação dessa hidrelétrica deu-se entre 1996 e 2006, a partir do que podemos estabelecer um paralelo com os casos mencionados anteriormente, sobretudo na questão da criminalização dos movimentos sociais. Analisando esse caso de Campos Novos, Zen (2005) relata que em março de 2005 foi decretada a prisão preventiva de dez lideranças do MAB sob a justificativa de "evitar a realização de manifestações por ocasião do 14 de março, Dia Internacional de Luta Contra as Barragens e também, do 22 de março, quando se comemora o Dia Internacional da Água”, conforme relatado no início deste capítulo. O mandado de prisão foi cumprido na madrugada do dia 12 de março de 2005, quando foram presos cinco pequenos agricultores e apreendidos "dezesseis veículos [...] utilizados para o cometimento de ilícitos", segundo a Promotoria (ZEN, 2005). 
Segundo o autor, a ação policial chamou a atenção pela quantidade de efetivo e equipamentos mobilizados. Os atingidos não presos naquela ocasião o foram nos dias seguintes, quando se apresentaram; outros se tornaram foragidos da justiça. Os agricultores presos foram encaminhados para o Presídio Regional, onde ficaram 23 dias, quando tiveram as prisões revogadas após declararem que não pretendiam promover atos contra a ordem pública. Ainda segundo o autor, "para 36 atingidos processados em ações criminais, são pedidas penas que vão de um a 30 anos de prisão por participarem do movimento e nove pessoas respondem a ação onde se pede indenização de R 1 milhão de reais por danos na usina de Campos Novos", ações estendidas aos apoiadores do MAB e tipificadas conforme as categorias já relatadas. Por outro lado, o autor ressalta que 237 famílias que participaram de alguma forma de pressão popular na hidrelétrica de Campos Novos tiveram reconhecidos direitos até então negados pelos propositores da obra (ZEN, 2005).

A criminalização dos movimentos sociais na UHE Campos Novos ilustra outro aspecto do período de privatização. A pressão popular ainda tem se mostrado a mais eficaz estratégia de conquista de demandas negadas pelos consórcios. Todavia, a criminalização funciona como forma de manchar a imagem do MAB perante a opinião pública, ao passo que age individualmente estigmatizando aqueles atingidos que assumem essas estratégias de pressão. Para além da criminalização, outra estratégia semelhante é a "judicialização" da questão hidrelétrica, aspecto que trataremos utilizando como pano de fundo o caso da UHE Foz do Chapecó, que teve seu processo de instalação no rio Uruguai, entre os anos entre 2001 e 2010, nos municípios de Alpestre-RS e Águas de Chapecó-SC. Essa hidrelétrica apresentou aspectos identificados também em outros casos, conforme referidos anteriormente. Perseguindo o objetivo do nosso trabalho, trataremos da questão da judicialização da UHE Foz do Chapecó, onde se destacam ações civis individuais e ação civil pública. 
Assim, como aconteceu nas outras hidrelétricas, firmou-se um termo de acordo entre o consórcio e uma associação representante dos atingidos. Nos casos em que determinadas famílias atingidas não concordassem com os valores ofertados pelas suas propriedades, teriam o direito de mover ações civis individuais contra o consórcio para que os valores fossem revistos. Na maioria dos casos, o consórcio lançou mão do depósito judicial, depositando a quantia que entendesse ser o valor justo para a indenização, enquanto o processo seguia o trâmite normal. Nessa modalidade ocorreu um confronto envolvendo o grupo de empresas privadas e estatais, com um amplo corpo jurídico e recursos financeiros para manter a disputa judicial por longo tempo contra uma família que detinha uma pequena área de terra, única fonte de sustento - quando não arrendatários ou agregados. Isso significa que essas famílias tinham pressa na solução da questão, pois disso dependia o seu sustento. Conhecedores da realidade desses processos, as empresas lançaram mão de estratégias de postergação da questão, que, ao final, forçavam as famílias a aceitarem um acordo com o consórcio por não terem recursos, nem tempo para estender a disputa na área judicial.

Além do ingresso individual na justiça para rever suas demandas, os atingidos tinham a possibilidade da ação civil pública. Na UHE Foz do Chapecó, foi movida uma ação civil pública tendo como réus o consórcio responsável pela obra e o Instituto Brasileiro do Meio Ambiente e dos Recursos Naturais Renováveis (Ibama), enquanto órgão licenciador. A ação suscitava três demandas principais: a proposta de construção de um canal artificial lateral para favorecer a piracema, baseado no projeto da UHE Itaipu; a revisão da proposta de vazão remanescente para o trecho a jusante da barragem, principalmente na parte entre o barramento e a casa de força (Volta Grande); a supressão de 100\% da vegetação de maior porte da área a ser alagada pelo reservatório da usina hidrelétrica, já que o consórcio, com o aval do Ibama, retirou apenas parte da vegetação. A emissão da licença de operação chegou a ser suspensa por conta da ação, todavia o consórcio recorreu ao Superior Tribunal de Justiça (STJ) com o 
apoio do Ibama, da Advocacia-Geral da União (AGU) e da Agência Nacional de Energia Elétrica (Aneel).

Como resultado dessa mobilização, o relator do processo no Superior Tribunal de Justiça (STJ) baseou-se em jurisprudência para fundamentar o argumento de que "a alegação de risco ao meio ambiente, deduzida no regimental, não fragiliza, diante dos elementos contidos nos autos, a ideia de que a paralisação do projeto de construção de usinas hidrelétricas, neste momento, poderá causar grave risco de prejuízos à ordem e à economia pública”. Foi reforçado pela continuação da obra por compor "um projeto maior, envolvendo a construção de outras usinas hidrelétricas, revela-se de extrema importância para a população brasileira, que vem crescendo a cada dia", fazia-se necessário o incremento da infraestrutura. O relator decidiu pela suspensão da liminar, "sobretudo, pelo fato de o órgão ambiental competente postular, mediante argumentos técnicos fortes, a continuidade do empreendimento", além do que, do ponto de vista econômico, "a liminar ora impugnada poderá causar grave lesão aos bens juridicamente tutelados pela lei de regência, cabendo o acolhimento da pretensão deduzida pelo IBAMA" (BRASIL/STJ, 2010).

Analisando os argumentos da decisão, percebemos que os julgamentos de casos específicos são feitos a partir de uma perspectiva macro sobre uma iminente crise energética que estaria sendo prevenida por meio de um plano que não podia ter o seu conjunto "prejudicado" por casos isolados. Depois, em que pese o meio ambiente e a economia, tende a prevalecer o segundo, com base no fato de que o atual nível de degradação do primeiro não chegaria a justificar a revisão do segundo, pelo menos por enquanto. Independentemente do resultado, é digno de nota que desde o início da ação civil pública (18 de junho de 2010) até a decisão em última instância (25 de agosto de 2010) passaram-se 61 dias. Considerando a sobrecarga de trabalho do Judiciário, essa agilidade é louvável, estabelecendo um comparativo com as ações individuais movidas pelos atingidos. É desalentador constatar que enquanto a primeira percorreu todas as 
instâncias em dois meses, as anteriores chegam a ultrapassar uma década, favorecendo ao consórcio propositor da obra em detrimento das famílias atingidas. De qualquer forma, com a decisão do STJ, o Ibama emitiu a licença de operação autorizando o funcionamento de mais uma hidrelétrica na bacia do Uruguai.

Constatamos que, a partir da década de 1990 até a metade da década de 2010, a relação entre atingidos e esfera político-estatal teve uma nova configuração, principalmente em razão da entrada do capital privado internacional no ramo energético, o que colocou novos e poderosos agentes na arena. Mesmo o PT, aliado histórico do MAB desde 2003, tendo ocupado a Presidência da República, não traduziu as políticas efetivas de proteção aos atingidos por barragens, sobretudo quando do lançamento do Programa de Aceleração do Crescimento (PAC) ${ }^{6}$ durante o primeiro governo Dilma (2010-2014), que fomentou o aumento da produção hidrelétrica no país a partir da construção de novas UHEs.

\section{Crescimento e difusão do MAB até 2015}

Até aqui acompanhamos de maneira detalhada a trajetória do MAB desde sua fundação. Nesta seção, exploramos de maneira analítica os intercursos dessa trajetória, dando ênfase às condições que possibilitaram ao movimento crescer e expandir-se. De forma mais ou menos comum a outros movimentos sociais, o MAB estrutura-se, cresce e difunde-se ao longo das últimas quatro décadas a partir do desencadeamento de uma série de processos articulados entre si. Eles dizem respeito, basicamente, à capacidade de os próprios militantes manterem o movimento em constante mobilização e à sua habilidade de aproveitar fatores externos, como a abertura de oportunidades políticas e o estabelecimento de relações externas

6 Com o PAC o governo federal previa o investimento de cerca de R 83 bi na construção de novas usinas hidrelétricas até 2017, sobretudo nas regiões Sul e Norte do país. Informação disponível em: <http://www.brasil.gov.br/cop/ panorama/o-que-o-brasil-esta-fazendo/matriz-energetica/print>. Acesso em: 20 fev. 2016. 
com redes de apoio. Essas dimensões de processos se combinam ao longo do tempo e se evidenciam na trajetória do movimento.

Sobre o aproveitamento de uma EOP, vimos como o contexto de abertura política favoreceu não somente a organização dos atingidos, como também a uma série de outros movimentos sociais que se articularam entre si e criaram um campo de movimentos sociais no país a partir da década de 1980 (GOHN, 1997). A mobilização dos atingidos por barragens aproveita a abertura política para sua formação e, posteriormente, vale-se de uma série de outras oportunidades por meio das quais estabelece relações com a esfera político-estatal. Por outro lado, a consolidação do movimento é fruto da conjunção entre fatores "externos" e "internos", dentre os quais a capacidade dos atingidos de prover a sustentação de sua organização.

Ao longo da história do MAB, percebemos os seguintes mecanismos de conformação do movimento: a) mediação - capacidade de estabelecer relações com indivíduos e grupos ${ }^{7}$ que possibilitam acessar espaços institucionais e demais redes pelas quais o movimento consegue angariar recursos e/ou ter suas demandas atendidas, ainda que parcialmente; b) captação de recursos - corresponde à capacidade de os atingidos acessarem recursos materiais que provenham da sustentação do movimento, os quais podem ser conseguidos a partir da própria contribuição dos atingidos e da relação com mediadores e parceiros que contribuem com o movimento ou lhes abrem espaços para que possam alcançá-los, como instituições religiosas, centrais sindicais e instituições de ensino; c) formação de redes de apoio - diz respeito ao estabelecimento de relações com movimentos sociais, centrais sindicais, partidos políticos, organizações não governamentais (ONGs) e outras entidades com as quais o MAB forma um bloco de unidade permanente ou momentâneo para ações políticas conjuntas. Esses mecanismos têm por objetivo o fortalecimento mútuo de organizações que compartilham de um projeto político comum. O Movimento

7 O Partido dos Trabalhadores (PT) é um histórico mediador do MAB. 
dos Trabalhadores Rurais Sem Terra (MST) e demais movimentos sociais componentes da Via Campesina e eventuais parceiros de mobilizações locais são exemplos.

Essas ações, somadas ao aproveitamento das EOPs, possibilitaram ao $\mathrm{MAB}$ crescer e difundir-se ao longo das últimas décadas. Vimos nas primeiras seções o quanto a mediação de entidades vinculadas às igrejas Católica e Protestante foi importante para que a então CRAB conseguisse dar seus primeiros passos e aos poucos lograsse sustentar-se, assim como, num momento seguinte, os sindicatos de trabalhadores rurais cumpriram o mesmo papel. A partir de 1991, quando a CRAB passou a denominar-se $\mathrm{MAB}$ e atuar em todas as regiões do país, os atingidos por barragens alcançam um novo patamar de mobilização e, se por um lado, dispõem de um movimento social mais estruturado e autônomo, por outro, o novo nível de atuação exige maior capacidade de captar recursos e acessar novas redes de apoio.

Outra dimensão importante de transformação do MAB ao longo do tempo diz respeito à questão discursiva ou simbólica. Da incipiente mobilização de colonos na bacia do rio Uruguai ao movimento articulado nacionalmente e que congrega em suas fileiras uma gama de categorias sociais de atingidos, o MAB foi passando por transformações internas que se traduzem na diversificação de demandas ao longo do tempo. De um movimento que reivindicava questões pontuais, como "não às barragens" e "águas para a vida e não para a morte", o MAB passou a articular-se discursivamente em torno de questões como um novo modelo energético, representado pelo slogan "água e energia não são mercadorias". A qualificação discursiva pela qual passa o MAB é indicativa do crescimento do movimento e da inserção em novas arenas de disputas.

O confronto simbólico intensifica-se na medida em que os opositores do movimento reforçam sua criminalização. Quando a criminalização se torna latente, o movimento é desafiado a justificar suas ações perante a opinião pública. Dessa forma, o movimento é instigado a disputar a 
veracidade dos fatos com seus opositores e ambos passam a enquadrar a realidade de acordo com seus sensos de justiça, interesses e, sobretudo, a partir de sua experiência diante do fenômeno social, a construção de barragens. Como os atingidos têm uma experiência fundamentalmente negativa em relação ao acontecimento, que coloca em xeque seus modos de vida, o MAB passa a questionar a correlação direta estabelecida por seus opositores entre produção de energia e desenvolvimento econômico e social. Portanto, as transformações estruturais e discursivas pela qual passa o movimento ao longo do tempo são o resultado de processos históricos que unem a conformação de eventos conjunturais - as EOPs - com a capacidade dos atingidos de se organizarem coletivamente.

Essa transformação possibilita ao movimento atingir um raio maior de atuação, aumentando seu poder de influência política ante os atingidos e ator capaz de confrontar com maior fôlego o Estado e consórcios privados. Todavia, o crescimento e a difusão não se concretizam sem tensões internas. Refletem-se na exigência cada vez maior de que parte dos atingidos se especializa e possa confrontar discursivamente seus opositores, já que passam a influenciar esferas de decisão mais abrangentes. O crescimento e a expansão do movimento provocam também a complexificação das redes internas, o que acarreta diferenciações internas e, geralmente, distanciamento entre lideranças e militantes de base. Em relação ao MAB, isso se expressa quando o movimento funda sedes em centros urbanos, como Porto Alegre, Brasília e São Paulo, onde lideranças ligadas à direção nacional do movimento se dedicam a questões macroestruturais do movimento e à formação de alianças. Por sua vez, lideranças locais e militantes de base ficam responsáveis por organizar o movimento no plano micro.

A especialização de quadros militantes, o distanciamento e a hierarquização do movimento, todavia, acabam por configurar-se numa exigência do crescimento e da difusão da organização coletiva. À medida que o movimento amplia os horizontes, sua capacidade de ação se firma; por outro lado, sua manutenção passa a exigir maiores esforços. Trata-se de 
um paradoxo enfrentado por, praticamente, todos os movimentos sociais que logram transcender suas fronteiras originais. De acordo com o que vimos ao longo do debate proposto neste capítulo, a estruturação da mobilização e a organização dos atingidos por barragens, assim como uma série de outros movimentos sociais ao longo da história, não são possíveis somente a partir do voluntarismo de seus militantes. Somado à capacidade de mobilização e organização, é necessário que uma estrutura de oportunidades políticas esteja madura para que os movimentos sociais possam desempenhar seu papel.

Sem embargo, um movimento social solidamente articulado é capaz de resistir com maiores chances de êxito diante de um cenário adverso, tal como o MAB enfrentou durante a década de 1990 os impactos das privatizações no setor elétrico. A segunda metade da década de 2010 apresenta novos desafios ao movimento, observando a queda de aliados políticos importantes com a consolidação do golpe institucional, refletidos na impunidade após um ano do desastre de Mariana, quando em novembro de 2015 centenas de famílias foram atingidas pelo rompimento de uma barragem de mineração na cidade mineira. Entretanto, se as EOPs são cruciais na definição das possibilidades de sucesso de um movimento social, não é o único fator determinante. $\mathrm{O}$ fechamento de uma janela de oportunidades políticas impõe dificuldades importantes aos movimentos sociais, mas é justamente nesse momento que a capacidade de mobilização e coesão interna possibilita resistir para que na abertura do próximo ciclo de oportunidades possa avançar na conquista de suas demandas.

\section{REFERÊNCIAS}

ALMEIDA, Alvenir Antonio de. As usinas hidrelétricas e os atingidos da bacia do Rio Uruguai: intenções entrecruzadas. Dissertação (Mestrado) - Programa de Pós-Graduação em História da Universidade de Passo Fundo, 2004. 
BAGGIO, Elaine Regina. Aspectos sobre a reprodução socioeconômica das unidades familiares rurais atingidas pela usina hidrelétrica Quebra Queixo. Dissertação (Mestrado) - Centro de Ciências Agrárias da UFSC, 2003.

BENFORD, Robert D. Master frame. In: SNOW, David A. et al. The WileyBlackwell Encyclopedia of Social and Political Movements. Blackwell Publishing, 2013. p. 1-2.

BERGAMASCO, Sônia Maria; NORDER, Luiz Antônio Cabello. O que são reassentamentos rurais. São Paulo: Brasiliense, 1996.

BOAMAR, Paulo Fernando de Azambuja. A implantação de empreendimentos hidroelétricos: o caso da UHE de Machadinho. Dissertação (Mestrado) - Programa de Pós-Graduação em Engenharia de Produção da UFSC. Florianópolis, 2003.

BRASIL. Superior Tribunal de Justiça-STJ. Voto do relator do processo de suspensão de liminar e de sentença $n^{\circ}$ 001270. Data da Publicação: DJ $27 / 08 / 2010$.

BRITO, Sebastião Berlinck. A Celesc: da instalação aos dias atuais. In: SANTOS, Sílvio Coelho dos; REIS, Maria José (Org.). Memória do setor elétrico na região Sul. Florianópolis: UFSC, 2002. p. 167-183.

CANALI, Gilberto Valente. A definição e a importância do projeto Uruguai. In: SANTOS, Sílvio Coelho dos; REIS, Maria José (Org.). Memória do setor elétrico na região Sul. Florianópolis: UFSC, 2002. p. 111-129.

CENTRO DA MEMÓRIA da Eletricidade no Brasil. Panorama do setor de energia elétrica no Brasil. Rio de Janeiro: Centro da Memória da Eletricidade no Brasil, 1988.

. Notas sobre racionamento de energia elétrica no Brasil (1940-1980). Rio de Janeiro: Centro da Memória da Eletricidade no Brasil, 1996.

DIANI, Mario. Social movement networks virtual and real. Information, Communication \& Society, Taylor \& Francis, v. 3, p. 386-401, 2000.

ELETROSUL. Bacia hidrográfica do rio Uruguai: estudo de inventário hidroenergético. [s. 1.]: Eletrosul, CNEC, 1979.

FEARNSIDE, Philip. Impactos ambientais da barragem de Tucuruí: lições ainda não aprendidas para o desenvolvimento hidrelétrico na Amazônia. Manaus: Instituto Nacional de Pesquisas da Amazônia, 2002. 
FERRET, Luis Airton. A CEEE e sua trajetória histórica. In: SANTOS, Sílvio Coelho dos; REIS, Maria José (Org.). Memória do setor elétrico na região Sul. Florianópolis: UFSC, 2002. p. 147-166.

GERMANI, Guiomar Inez. Expropriados. Terra e água: o conflito de Itaipu. Salvador: Edufba; Ulbra, 2003.

GOHN, Maria da Glória. Teoria dos movimentos sociais: paradigmas clássicos e contemporâneos. São Paulo: Loyola, 1997.

GONÇALVES JUNIOR, Dorival. Reformas na indústria elétrica brasileira: a disputa pelas "fontes" e o controle dos excedentes. Tese (Doutorado) Programa Interunidades de Pós-Graduação em Energia da Universidade de São Paulo (EPUSP - FEA - IEE - IF/USP). São Paulo, 2007.

JASPER, James; GOODWIN, Jeff; POLLETTA, Francesca. Passionate politics. Chicago: University of Chicago Press, 2001.

LIMA, José Luiz; BARBALHO, Arnaldo Rodrigues; CARVALHO, José Marcondes Brito de. A trajetória do setor de energia elétrica na década de 1970. In: CMEB. Ciclo de palestras: a Eletrobras e a história do setor de energia elétrica no Brasil. Rio de Janeiro: Centro da Memória da Eletricidade no Brasil, 1995. p. 163-219.

LIMA, José Luiz; PENNA, João Camilo; CAMOZZATO, Izaltino. A trajetória do setor de energia elétrica na década de 1980. In: CMEB. Ciclo de palestras: a Eletrobras e a história do setor de energia elétrica no Brasil. Rio de Janeiro: Centro da Memória da Eletricidade no Brasil, 1995. p. 221-262.

MAGALHÃES, Sônia Barbosa. Lamento e dor. Uma análise socioantropológica do deslocamento compulsório provocado pela construção de barragens. Tese (Doutorado) - Programa de Pós-Graduação em Ciências Sociais da Universidade Federal do Pará em co-tutela com a École Doctorale Vivant et Sócietés da Universidade Paris, 13. Belém: UFPA, 2007.

McADAM, Doug; TARROW, Sidney; TILLY, Charles. Dynamics of Contention. New York and Cambridge: Cambridge University Press, 2001.

McCARTHY, John D.; ZALD, Mayer N. Resource mobilization and social movements: a partial theory. The American Journal of Sociology, v. 82, n. 6, p. 1212-1241, May 1977.

MORAES, Maria Stela Marcondes de. No rastro das águas: pedagogia do movimento dos atingidos pelas barragens da bacia do rio Uruguai (RS/SC) - 1978-1990. Tese (Doutorado) - Departamento de Educação, PUCRJ, 1994. 
. No rastro das águas: organização, liderança e representatividade dos atingidos por barragens. In: NAVARRO, Zander (Org.). Política, protesto e cidadania no campo: as lutas sociais dos colonos e trabalhadores rurais no Rio Grande do Sul. Porto Alegre: UFRGS, 1996.

. O movimento dos atingidos pelas barragens da bacia do rio Uruguai e a ação político-educativa dos mediadores. Revista Brasileira de Educação, n. 1, p. 80-92, 1996a.

MOVIMENTODOS ATINGIDOS PORBARRAGENS(MAB). Criminalização contra os defensores de direitos humanos na implantação de hidrelétricas na bacia do rio Uruguai. Brasília, 2005. (Relatório).

A luta dos atingidos por barragens contra as transnacionais, pelos direitos e por soberania energética. São Paulo-SP, 2008. (Cartilha).

MOVIMENTO NACIONAL DE DIREITOS HUMANOS (MNDH). A criminalização dos movimentos sociais no Brasil: relatório de casos exemplares. Organizado por Rosiana Pereira Queiroz. Brasília: MNDH; Passo Fundo: IFIBE, 2006.

OLSON, Mancur. A lógica da ação coletiva. São Paulo: Edusp, 1999.

POLI, Odilon Luiz. Leituras em movimentos sociais. Chapecó: Grifos, 1999.

PROCHNOW, Miriam. Entendendo o caso. In: PROCHNOW, Miriam (Org.). Barra Grande: a hidrelétrica que não viu a floresta. Rio do Sul: Apremavi, 2005. p. 6-8.

REIS, Maria José; BLOEMER, Neusa Maria Sens; NACKE, Aneliese. Empreendimentos pioneiros na produção de energia elétrica. In: SANTOS, Sílvio Coelho dos; REIS, Maria José (Org.). Memória do setor elétrico na região Sul. Florianópolis: UFSC, 2002. p. 31-76.

REIS, Maria José. O movimento dos atingidos por barragens: atores, estratégias de luta e conquistas. In: SEMINÁRIO NACIONAL NPMS/USC, II. Anais... Florianópolis-SC, 2007. p. 473-501.

ROCHA, Humberto José da. Relações de poder na instalação de hidrelétricas. Passo Fundo-RS: UPF, 2013.

- O controle do espaço-tempo nos processos de instalação de hidrelétricas. Tempo Social, São Paulo, v. 26, n. 1, p. 259-280, 2014. 
A criminalização dos movimentos sociais ante a instalação de uma hidrelétrica no rio Uruguai (Brasil): uma discussão entre o legal e o legítimo. Ideias, Campinas-SP, v. 8, n. 1, 2014a.

ROCHA, Humberto José da; GODOI, Emilia Pietrafesa de. Configuração social e suas implicações na negociação para a instalação da UHE Foz do Chapecó. In: REUNIÃO DE ANTROPOLOGIA DO MERCOSUL, IX. Anais... Curitiba-PR, 2011.

ROCHA, Humberto José da; TEDESCO, João Carlos. A judicialização da questão hidrelétrica no Brasil. In: CONGRESO ALAS, XXIX. Acta científica. Santiago-Chile, 2013.

ROSSATO, Alexania. A recepção de rádio e televisão por jovens do movimento dos atingidos por barragens: as representações da classe popular. Dissertação (Mestrado) - Programa de Pós-Graduação em Comunicação da UFSM. Santa Maria, 2008.

ROTHMAN, Franklin Daniel. A emergência do movimento dos atingidos pelas barragens da bacia do rio Uruguai (1979-1983). In: NAVARRO, Zander (Org.). Política, protesto e cidadania no campo: as lutas sociais dos colonos e trabalhadores rurais no Rio Grande do Sul. Porto Alegre: UFRGS, 1996.

SANTOS, Sílvio Coelho dos. A história da eletricidade no Sul. In: SANTOS, Sílvio Coelho dos; REIS, Maria José (Org.). Memória do setor elétrico na região Sul. Florianópolis: UFSC, 2002. p. 19-30.

. A Eletrobras e suas subsidiárias: projetos termo e hidrelétricos no Sul. In: SANTOS, Sílvio Coelho dos; REIS, Maria José (Org.). Memória do setor elétrico na região Sul. Florianópolis: UFSC, 2002a. p. 99-110.

SANTOS, Sílvio Coelho dos; NACKE, Aneliese. A importância estratégica do setor elétrico no cenário da região Sul. In: SANTOS, Sílvio Coelho dos; REIS, Maria José (Org.). Memória do setor elétrico na região Sul. Florianópolis: UFSC, 2002. p. 204-211.

A implantação da UHE Machadinho num cenário privatizado: um caso para reflexão. In: REIS, Maria José; BLOEMER, Neusa Maria Sens (Org.). Hidrelétricas e populações locais. Florianópolis: UFSC, 2001. p. 71-92.

SCOTT, Parry. Negociações e resistências persistentes: agricultores e a barragem de Itaparica num contexto de descaso planejado. Recife-PE: UFPE, 2009. 
SEYFERTH, Giralda. As contradições da liberdade: análise de representações sobre a identidade camponesa. Revista Brasileira de Ciências Sociais, Rio de Janeiro, v. 18, p. 78-95, 1992.

SIMON, Camilo. A revolução silenciosa: a saga da eletrificação rural cooperativada do RS. Porto Alegre: Sescoop, 2011.

SNOW, David A.; BENFORD, Robert D. Framing processes and social movements: an overview and assessment. Annual Review of Sociology, v. 26, p. 611-639, 2000.

. Master frames and cycles of protest. In: MORRIS, A.; MUELLER, C. M. (Org.). Frontiers in social movement theory. London: Yale University Press, 1992. p. 133-155.

SIMON, Camilo et al. Frame alignment processes: micromobilization, and movement participation. American Sociological Review, v. 51, n. 4, p. 464-481, 1986.

TARROW, Sidney. O poder em movimento: movimentos sociais e confrontos políticos. Petrópolis: Vozes, 2009.

TILLY, Charles. From mobilization to revolution. Reading: Addison-Wesley, 1977. VENTURA, Zuenir. 1968: o ano que não terminou. Rio de Janeiro: Nova Fronteira, 1988.

ZEN, Eduardo Luiz. Ditadura na barranca dos rios brasileiros: perseguição e criminalização de militantes da luta contra as barragens. Disponível em: $<$ www.mabnacional.org.br/artigo/ditadura-na-barranca-dos-rios-brasileirospersegui-e-criminaliza-militantes-da-luta-contra-ba>. Acesso em: 5 nov. 2009.

ZIMMERMANN, Neusa de Castro. Os desafios da organização interna de um assentamento rural. In: MEDEIROS, Leonilde et al. (Org.). Assentamentos rurais: uma visão multidisciplinar. São Paulo: Unesp, 1994. p. 205-224. 